\title{
The role of musical possible selves in supporting subjective well-being in later life
}

\section{Abstract}

There is now an accepted need for initiatives that support older people's well-being. There is increasing evidence that active engagement with music has the potential to contribute to this. This paper explores the relationship between musical possible selves and subjective well-being in later life. The research reported here formed part of a larger project that focused on how active music-making could support positive cognitive, social and emotional outcomes. The research comprised three UK case study sites, each offering diverse musical activities. A sample aged 50+ (total $\mathrm{N}=398$ ), some of whom were novices and others who are more experienced, was recruited to complete questionnaires that included open questions and measures of well-being. In addition, individual interviews $(n=29)$ and focus groups $(n=15)$ were carried out, where participants in musical activities reflected on the meaning and function of musicmaking in their lives. The interpretation presented here suggests that through music many older people found a means by which they were able to formulate well understood and highly esteemed versions of their possible future selves. This, in turn, may have been a significant factor in helping to navigate the process of ageing in later life with enhanced subjective well-being, including a sense of purpose, a significant degree of autonomy and a strong sense of social affirmation.

Key words: possible selves; music; ageing; identity 
Creech, A., Hallam, S., Gaunt, H., Pincas, A., McQueen, H., \& Varvarigou, M. (in press). The role of musical possible selves in supporting subjective well-being in later life. Music Education Research.

\section{Introduction}

This paper explores how the development of possible selves (Markus and Ruvolo, 1989) within the context of active music-making may contribute to sustained well-being in later life. There is a growing body of compelling evidence that in the latter part of our lives participation in music may provide a source of enhanced social cohesion, enjoyment, personal development and empowerment (for example, Creech et al.,, in press; Coffman, 2002; Cohen et al., 2007; Sixsmith and Gibson, 2007). According to Iwasaki, Coyle and Shank (2010) music is one of several culturally meaningful and creative leisure activities that are 'spiritually refreshing' and promote self-expression, positive health and well-being.

The issue of whether older adults derive enhanced subjective well-being through formulating possible musical selves is relevant within our current demographic context, characterized by an ageing population. In the UK, the number of people over 65 is projected to double by 2071, reaching 21.3 million (GOScience, 2008), while in the USA the proportion of the population in this age bracket is projected to reach 13 per cent by 2030 (Coffman, 2002). Amongst our ageing population the 'oldest old', the so-called Fourth age (i.e. over 75 years of agem according toLaslett, 1989) comprise the fastest growing group. In England and Wales the number of centenarians is rising by eight per cent per year (Office for National Statistics, 2011), while it is estimated that globally this group will reach the one million mark by 2030 (Yong, 2009).

These extraordinary demographic changes have raised many challenges. For example, the UK based Relatives and Residents Association (R\&RA, 2010) estimates that at least eight per cent of older people in care in England are living in social isolation. Within a context where the number of old people suffering from depression is increasing (Age concern, 2008) there is 
Creech, A., Hallam, S., Gaunt, H., Pincas, A., McQueen, H., \& Varvarigou, M. (in press). The role of musical possible selves in supporting subjective well-being in later life. Music Education Research.

an accepted need for initiatives that support older people's well-being and productivity (Jamieson, 2007). The potential for music-making, in particular, to support positive health, well-being and quality of life amongst older adults has generated much interest and is a growing research area (for a review of relevant literature, see Creech et al., in press). The key messages from this body of research are that 1) music-making is a joyful and creative activity that all humans, regardless of age, have an entitlement to, and 2) engagement with music continues to contribute to quality of life throughout these latter stages of the life-course, regardless of cognitive capacity (Bailey, Nilsson and Cohen, 2002) or musical background (Hays and Minichiello, 2005).

In this paper, we explore the idea that active music-making may act as a medium through which older people may develop possible musical selves with the potential to contribute to underlying dimensions of subjective well-being that have been identified as 1) a sense of purpose in life, 2) a sense of autonomy in goal pursuit and 3) a sense of social affirmation, i.e. validation as a valued and worthwhile member of a social network (Creech et al, 2012) ).

\section{The universality of music and its relationship with well-being}

Music is at the very essence of our humanity. Along with language, music distinguishes us from other species. For many thousands of years music, and in particular singing, has had an important role to play in the functioning of society. There is now general agreement that music is a universal trait of humankind (Blacking, 1995). Furthermore, there is strong evidence that, just as with language, a normal distribution of musical proclivity may be found amongst the human population. This evidence suggests that the vast majority of us is 
Creech, A., Hallam, S., Gaunt, H., Pincas, A., McQueen, H., \& Varvarigou, M. (in press). The role of musical possible selves in supporting subjective well-being in later life. Music Education Research.

musical and that from infancy and subsequently throughout the life-course we actively engage with music in our everyday lives (see Creech and Ellison, 2010, for a review).

Some have argued that music, along with the other arts, has no evolutionary significance or practical function and exists simply because of the pleasure that it affords (Pinker, 1997). Others, though, have suggested a range of evolutionary purposes (Huron, 2003). For example Cross (2009) noted a close link between music and social behaviour. Music is seen as being significant because of its bonding effect and its association with cooperative, communicative within group interactions (Hagen and Bryant, 2003). Furthermore, the communicative power of music is thought to be complementary to that of language, rather than as a substitute for language (Cross, 2009). Underlying these debates is the assumption that homo sapiens as a species has the propensity for musical development and that musicality is as universal as linguistic ability (Blacking, 1971; Wallin, Merker and Brown, 2000). It may thus be argued that music has a central role to play in maintaining well-being amongst humans, across cultures and contexts.

The responses of human beings to music go beyond 'sound'. Music can be experienced physiologically (e.g. changes in heart rate); through movement; through mood and emotion; and cognitively (through knowledge and memories, which may be personal, or related to the music itself, e.g. its style or period). The fact that music has physical, emotional and cognitive effects may be the key to its powerful relationship with well-being (Hallam, 2010).

\section{Possible selves}

The idea of 'possible selves' (Markus and Nurius, 1986) refers to ideal and hoped-for selves or alternatively selves that are feared and dreaded. These future oriented selves comprise the 
Creech, A., Hallam, S., Gaunt, H., Pincas, A., McQueen, H., \& Varvarigou, M. (in press). The role of musical possible selves in supporting subjective well-being in later life. Music Education Research.

'motivational component of the self system' (Frazier et al., 2002: 308). Possible selves are domain specific, guiding action and influencing decisions with regard to what to expend effort on and what to abandon (Smith and Freund, 2002). Possible selves are also dynamic, in the sense that individuals are thought to reframe their possible selves in response to life transitions, motivated by the desire to preserve well-being (Cross and Markus, 1991).

Some myths about old age, including the notion that older people do not like change and that they are not interested in learning anything new have been documented and critiqued by Withnall, McGivney and Soulsby (2004) and Withnall (2010). Smith and Freund (2002) applied a possible selves perspective in exploring such myths, focusing on whether the motivational orientations of possible selves amongst older people would indicate desires for self-improvement or, alternatively, would be concerned with efforts to prevent losses. Positive and negative possible selves were collected via face-to-face interviews from a sample of 206 people aged 70 - 103, drawn from the Berlin Ageing Study. Four years later the possible selves interviews, whereby participants were asked to generate two hoped-for and two feared possible selves, were repeated. Across all ages of participants, the dominant motivational orientation for hoped-for selves was the desire to attain, achieve or reexperience something, while for feared possible selves the dominant orientation was avoidance. The recorded possible selves were found to be highly personalized, dynamic and varied, covering a range of domains, even amongst the oldest old. This research thus suggested that 'the future-oriented motivational system associated with possible selves functions relatively well into very old age' (Smith and Freund, 2002: 498). The view put forth by Withnall, McGivney and Soulsby (2004) is thus supported; late adulthood need not be interpreted as a period of disengagement from planning for new possibilities and experimenting with new possible selves. 
Creech, A., Hallam, S., Gaunt, H., Pincas, A., McQueen, H., \& Varvarigou, M. (in press). The role of musical possible selves in supporting subjective well-being in later life. Music Education Research.

Frazier et al (2002) suggest that future oriented images of self amongst older people are underpinned by identity relevant goals. Their research focused on the hoped-for and feared possible selves reported from 151 residents, aged 60 to 96, of senior residential communities in Florida. Overall, leisure, health and enhanced abilities/education were found to be the most important hoped-for possible selves. When age differences were examined it was found that while abilities/education were the most important domain for possible selves amongst those aged in their 60s and 70s, health was the most important domain for those aged $80+$. The researchers concluded that through pursuing goals associated with possible selves, individuals continued to construct their own development through the latter stages of life. Thus, possible selves were interpreted as having the potential to provide insight into how goals can shape the process of ageing.

King and Hicks (2007: 626) gathered responses to quantitative quality of life measures and analysed written possible self narratives from adults who had experienced major life transitions. The potential 'crisis of goal change' was conceptualised as leading to 'lost possible selves'. Significant life transitions may constrain possible selves (Smith and Freund, 2002) and involve disengagement from valued and cherished goals. These lost possible selves, according to King and Hicks (2007: 626), lead to a re-evaluation 'of one's place in the world' and thus play an integral role in adult ego development and attainment of subjective well-being.

For possible selves to support positive well-being, they must be salient, in the sense that they are both psychologically accessible and personally meaningful (Rossiter, 2007). Ibarra (1999) suggests that this salience is strengthened when possible selves are constructed 
Creech, A., Hallam, S., Gaunt, H., Pincas, A., McQueen, H., \& Varvarigou, M. (in press). The role of musical possible selves in supporting subjective well-being in later life. Music Education Research.

through the observation of role models, experimentation with provisional selves and evaluation of new conceptions against internal and external standards. The more vivid the possible selves become, the more they motivate individuals to strive towards narrowing the gap between the current self and the possible self.

King and Hicks (2007: 627) emphasized the importance of salience and elaboration in their discussion of how adaptive possible selves may influence adult development. By salience they referred to the extent to which the possible self is chronically available and the individual is engaged with the associated goals. The concept of elaboration refers to the richness of the narrative individuals can generate when asked about their possible selves, including the vividness, detail and emotionality. Highly elaborated possible selves allow the individual to vicariously experience the desired or feared self. Leondari, Syngollitu, and Kiosseoglou (1998) added that individuals with well-elaborated possible selves are not only better able to face failures but they also have access to more strategies to avoid failure. A key point proposed by King and Hicks (2007) is that positive subjective well-being requires that lost possible selves cease to be salient to individuals. However, healthy ego-development has been associated with elaboration of lost possible selves. In other words, adults need to relinquish the emotional investment in previously cherished possible selves yet also retain an elaborate understanding of those lost selves, in order for new salient possible selves and personal growth to emerge.

The research reported here intended to address the following questions:

- Do older people rediscover or generate possible positive musical selves when actively engaging in making music with others? 
Creech, A., Hallam, S., Gaunt, H., Pincas, A., McQueen, H., \& Varvarigou, M. (in press). The role of musical possible selves in supporting subjective well-being in later life. Music Education Research.

- Does the generation of positive possible musical selves relate to the enhancement of self-reported well-being?

\section{Methods}

The research reported in this paper formed part of a larger project that investigated the relationship between active engagement in music-making and psychological well-being, amongst older people (Hallam et al., 2013). The overall aim of the project was to investigate the role that participation in creative musical activities had in the lives of older people, the extent to which this may have impacted upon their social, emotional and cognitive wellbeing, and the particular processes through which this occurred.

In addition to the in-depth interviews, focus groups and written responses to open questions that form the basis of the analysis presented here, participants in the study completed quantitative measures of subjective well-being, conceptualised as basic needs (Deci and Ryan, 2008) and quality of life (Wiggins et al., 2007; 2008). As reported in Creech et al. 2012 three underlying factors contributing to subjective well-being were revealed when these quantitative subjective well-being measures were combined in a principal components analysis. The first factor related to a sense of purpose and a positive outlook on life. The second showed high ratings on statements relating to autonomy and control, while factor 3 focused on positive social relationships, competence and a sense of recognized accomplishment. Accordingly, the three factors were labeled as 1) purpose, 2) autonomy/control and 3) validation/social affirmation (see Creech et al., 2012for elaboration of these underlying constructs). 
Creech, A., Hallam, S., Gaunt, H., Pincas, A., McQueen, H., \& Varvarigou, M. (in press). The role of musical possible selves in supporting subjective well-being in later life. Music Education Research.

\section{Procedures}

Only the methodology relevant to the findings reported here is included in this paper. Data were collected from three case studies of musical community involvement based at: the Sage, Gateshead; the 'Connect' programme of the Guildhall School of Music and Drama; and Westminster Adult Education Service.

The Sage Gateshead: The Silver Programme at the Sage Gateshead aims to develop the broadest possible range of musical opportunities for people over the age of 50, by providing a programme of supported daytime music workshops and events in a structured, relaxed and enjoyable atmosphere. Participants have the opportunity to perform regularly in public concerts. The weekly 'Silver Programme' actively involves 1000 people aged 50 and over in an eclectic spread of music activities including singing of many kinds, steel pans, guitars, recorder, folk ensemble and samba.

The Connect Programme of the Guildhall School of Music and Drama: The Guildhall School of Music and Drama Connect Programme runs community projects with people of all ages in East London. 'Connect' music projects are distinctive in that their focus is on activities where participants create and perform music together, linking story-telling and reminiscing to creative music-making. The programmes run by 'Connect' to date have largely focused on young people. For the 'Music for Life' research project the musical activities with older people took place in the community rooms of sheltered housing accommodation in East London. These musical activities included intergenerational music sessions involving the older people making music together with children from local primary schools. 
Creech, A., Hallam, S., Gaunt, H., Pincas, A., McQueen, H., \& Varvarigou, M. (in press). The role of musical possible selves in supporting subjective well-being in later life. Music Education Research.

The Westminster Adult Education Service: Westminster Adult Education Service (WAES) music department runs a wide range of musical programmes catering for students at all levels of expertise. Courses in a range of musical genres are offered, specializing in singing, playing instruments, sound engineering and using sequencers, music theory and composing. In 2010-11, older learners participated in courses as diverse as singing, music technology, radio production, piano, music theory, guitar and ukulele. The WAES music department is distinctive in that it operates satellite centres in residential care homes where older people participate in choir and music appreciation classes.

The data that were interrogated for the purposes of this paper were drawn from the sources outlined below.

\section{Questionnaires - open questions}

Participants in the music activities completed questionnaires at the beginning and end of the period of the research. The questionnaires included open questions relating to participants' views about the benefits of active music-making as well as barriers to participation.

\section{Focus group interviews with participants}

The focus group interviews explored issues relating to the experience of being a member of a musical group. Participants in focus groups were asked to describe the best aspects of participating as well as the challenges. Issues were also raised relating to how they became involved, any access or provision issues, what they enjoyed or would like to change, their 
Creech, A., Hallam, S., Gaunt, H., Pincas, A., McQueen, H., \& Varvarigou, M. (in press). The role of musical possible selves in supporting subjective well-being in later life. Music Education Research.

expectations of the activity and the facilitator/leader's expectations of them, and their views on performance.

\section{Individual semi-structured interviews with participants}

The questions that were asked during individual interviews focused on the individuals' involvement in music, their musical preferences, their experiences from music sessions and performances, their perception of what makes a 'good leader' of musical activities, their thoughts on the role of musical activities in their local communities and possible connection between music participation and wellbeing.

\section{The sample}

Questionnaires were distributed to participants on all three sites through the facilitators of the music groups. 398 questionnaires were returned to the researchers, representing a response rate of 56 per cent.

A smaller sample of participants took part in individual semi-structured interviews and focus group interviews. In total, 29 individual interviews and 15 focus group interviews ( $\mathrm{n}=76$ participants) were carried out. Interviewees were identified via questionnaire responses, where individuals indicated whether they would agree to be interviewed. Members of the focus groups were selected in consultation with the music facilitators and on the basis of their willingness to participate. Participants provided informed consent prior to the interviews and focus groups. They were assured that they were under no compulsion to participate and could withdraw at any point. Assurances were also provided with regard to anonymisation of the data. 
Creech, A., Hallam, S., Gaunt, H., Pincas, A., McQueen, H., \& Varvarigou, M. (in press). The role of musical possible selves in supporting subjective well-being in later life. Music Education Research.

Of the whole sample $(n=398)$ who filled in the project questionnaires, eighty per cent of this sample was female and the majority was white, despite attempts of the research team to recruit members of a range of ethnic minority groups. The age range was 43-92 with 92 over the age of 75. The majority had been involved in professional occupations.

Seventy-six per cent of the music participants had some kind of prior musical experiences. Twenty-nine per cent classed themselves as musical beginners. Only 4 per cent described themselves as 'very good', while the remainder described themselves as either average or good. Seventy three per cent indicated that they could read music but for most this was at a basic level. Only 8 per cent reported that they had 'very good' reading skills. Eleven per cent reported that music played a central role in their lives; for the remainder music had 'no importance' or they 'listened to music from time to time'. The participants had a wide range of musical preferences, the strongest preference being for classical music, the least popular being reggae and electronic music.

A total of 29 individuals were interviewed, including 16 females and 13 males. Their ages ranged from to $59-92(\underline{\mathrm{M}}=76)$. Fifteen focus group interviews were carried out, ranging in size from four to eight participants. The gender and age of focus group participants were not recorded.

\section{Analysis}

All of the qualitative data were transcribed in full and analysed using a process devised by Cooper and McIntyre (1993). The process involved:

1. Reading a random sample of scripts; 
Creech, A., Hallam, S., Gaunt, H., Pincas, A., McQueen, H., \& Varvarigou, M. (in press). The role of musical possible selves in supporting subjective well-being in later life. Music Education Research.

2. Identifying points of similarity and difference among these transcripts in relation to the research questions;

3. Generating theories against a new set of transcripts;

4. Testing theories against a new set of transcripts;

5. Testing new theories against transcripts that have already been dealt with;

6. Carrying all existing theories forward to new transcripts;

7. Repeating the above process until all data have been examined and all theories tested against all data (Cooper and McIntyre, 1993).

NVivo was used to support this process. Two researchers undertook the initial analysis, generating a thematic coding structure. This coding structure was then monitored by two additional researchers. The four researchers met as a team and discussed areas of similarity and difference in interpretation, before finalizing the final set of emergent themes, organised as a set of 'free nodes'. Following this, an inductive approach was taken, organizing themes around the overarching concepts of 'possible self' and 'lost possible self'. These overarching concepts were then interrogated for qualitative evidence of a relationship between possible selves and underlying components of subjective well-being that were identified as 'purpose', 'autonomy/control' and 'social affirmation' (see Creech et al. 2012; Hallam et al., 2013)

\section{Results}

Several themes emerged relating to the participants' development of self-concept as musicians, their engagement in music as a new life opportunity and redefining lost musical selves through reminiscing about past musical experiences. The data below show how these themes may be interpreted as linking with the construct of possible selves and the three factors of well-being; purpose, autonomy and social affirmation that emerged from the 
Creech, A., Hallam, S., Gaunt, H., Pincas, A., McQueen, H., \& Varvarigou, M. (in press). The role of musical possible selves in supporting subjective well-being in later life. Music Education Research.

analyses of the quantitative measures of subjective wellbeing in the questionnaires (see Figure 1).

Figure 1: Possible selves and the three factors of well-being HERE

\section{Rediscovering and generating possible musical selves}

At first when I started playing this - because I have never seen a ukulele before - I had played guitar years ago but I taught myself. So at first it was like this foreign object and it was so difficult and suddenly one day I thought 'it feels like part of me' and I don't have to look any more.

For some, music was a vehicle for redefining one's identity as a musician or rediscovering a lost possible musical self. Through music-making, participants developed or, in some cases rekindled a strong musical identity. Some participants now considered themselves to be musicians. This musical self-concept was bolstered by a sense of being part of a community of musicians, by having performed with their professional musician facilitators and because they spent many hours making music and practising. Participants also referred to how they thought others perceived them; being a 'musician' was a new role, bringing with it interest and affirmation (Table 1 HERE

) .

\section{Table 1 HERE}

For 'novices' who had no early experience of music-making, participation in community groups now provided a second chance to 'be a musician', which in some cases was something that had never previously been considered (Table 2). 
Creech, A., Hallam, S., Gaunt, H., Pincas, A., McQueen, H., \& Varvarigou, M. (in press). The role of musical possible selves in supporting subjective well-being in later life. Music Education Research.

\section{Table 2 HERE}

During the interviews and in their questionnaire responses many participants talked in detail about early memories - both positive and negative - in relation to music in their life. They reminisced about the role of music in their family life as children as well as some of their music-teachers' influence on them. In some instances childhood experiences had influenced the extent of their lifelong engagement or disengagement in active music-making. It was evident that music was a powerful medium through which participants could discover a sense of continuity in their lives, reconnecting with some of their earliest memories and experiences. Through engagement with music individuals, in some cases, sustained possible musical selves, while in others they re-discovered lost musical selves (Table 3).

\section{Table 3 HERE}

\section{Musical possible selves and subjective well-being}

Analysis of quantitative well-being measures reported elsewhere (Creech, et al. 2012) suggested that subjective well-being could be conceptualized as comprising three underlying constructs: purpose, autonomy/control and social affirmation. The qualitative data presented in this paper strongly indicated that highly valued possible musical selves provided a sense of purpose in the lives of many participants. This concept of 'purpose' was underpinned by the notion that music-making provided structure in daily and weekly routines and that it was the medium through which participants worked towards goals and acquired new skills (Table 4). Participants placed a high value on their music-making and understood the detailed steps that 
Creech, A., Hallam, S., Gaunt, H., Pincas, A., McQueen, H., \& Varvarigou, M. (in press). The role of musical possible selves in supporting subjective well-being in later life. Music Education Research.

needed to be undertaken in order to develop as musicians. For example, they organised other activities around this commitment, including time for practicing. Through music, participants developed possible selves as skilled musicians who belonged to a community characterised by both an individual as well as a shared sense of purpose.

\section{Table 4 HERE}

Possible musical selves were also related to a sustained sense of autonomy and control in individuals' lives. Some participants spoke of having the freedom, in later life, to explore these possible musical selves. Others spoke of how 'being a musician' provided the opportunity for self expression and individual creativity. Many participants spoke of having, through music, developed confidence; being a 'musician' was linked with growing confidence and control over life, both in musical and non-musical contexts (Table 5).

\section{Table 5 HERE}

For many participants performances offered an important opportunity to receive social affirmation and validation as a 'musician', sharing the results of their hard work with friends and relatives. Some did not enjoy performances when they perceived their contribution to be a limited, token gesture. On the whole, while performances seemed to be a significant part of the participants' possible musical selves, it was important that participants perceived their contribution to be valued and meaningful and not short 'token' gestures (Table 6).

\section{Table 6 HERE}


Creech, A., Hallam, S., Gaunt, H., Pincas, A., McQueen, H., \& Varvarigou, M. (in press). The role of musical possible selves in supporting subjective well-being in later life. Music Education Research.

The qualitative data suggested that developing musical possible selves provided a means by which participants could make a highly valued contribution to their communities. In this vein, possible musical selves provided individuals with a medium through which they could support others and provide pleasure and enjoyment for others. In turn, these individuals experienced a strong sense of affirmation as a valued member contributor within their immediate social context.

\section{Discussion}

This paper explored qualitative data generated from older people who participated in active music-making, focusing on whether the development of musical possible selves in later life may contribute to satisfying three underlying dimensions of subjective well-being: 1) purpose, 2) autonomy/control and 3) validation through social affirmation (see Creech et al., 2012).

The data presented here suggest that domain-specific musical possible selves may function, as Smith and Freund (2002) claimed, as a guide to actions and choices with regard to what to expend effort on. For example, participants in music-making structured their time around their musical commitments and engaged in self-directed practice in order to pursue desired musical outcomes. For some participants, experimentation with provisional musical selves was understood in terms of commitment, routine and application to practising in pursuance of new skills.

The participants in this study demonstrated how their musical possible selves were in some instances made accessible through life transitions such as retirement. This resonates with the 
Creech, A., Hallam, S., Gaunt, H., Pincas, A., McQueen, H., \& Varvarigou, M. (in press). The role of musical possible selves in supporting subjective well-being in later life. Music Education Research.

view put forth by Cross and Markus (1991) who suggested that possible selves are dynamic and that major life transitions may offer the scope and space for new possible selves to be formed. Music participants' responses also suggested that their musical possible selves were underpinned by the motivation to improve oneself, to gain new experiences and new skills. This supports the views put forth by Cross and Markus (1991) and Withnall, McGivney and Soulsby (2004), who challenged the view that later life is characterised by a drive to simply prevent losses, suggesting that possible selves in later life may be focused on experimentation and embracing changing identities (also see Brookfield, 1986).

It was striking that many participants formed future oriented images of their selves that were framed by the idea that 'I am a musician'. For many, this was a new identity and one that they experimented tentatively at first but with growing confidence. Markus and Nurius (1986) suggest that possible selves may be derived from past selves. In this sense, some participants may have drawn on past experiences, rediscovering lost possible selves. This may have involved a reinvestment in previously cherished possible selves (King and Hicks, 2007). Through access to musical engagement in a social context, these lost possible selves may have become imbued with the salience that King and Hicks (2007) and Rossiter (2007) refer to, whereby the possible self is a valued, personally meaningful and psychologically accessible. Furthermore, active engagement with peers and expert facilitators, musical possible selves could be constructed in elaborate detail and evaluated through self and peer feedback and social affirmation.

Participants in this study who claimed to have little or no previous experience of active music-making, alongside those who had some prior identity as a musician, were able to access and experiment with provisional selves in the domain of music. It may be that the 
Creech, A., Hallam, S., Gaunt, H., Pincas, A., McQueen, H., \& Varvarigou, M. (in press). The role of musical possible selves in supporting subjective well-being in later life. Music Education Research.

power and universality of music (Blacking, 1995; Hallam, 2010) is such that, irrespective of early opportunities, throughout the life-course humans sustain the capacity to respond in powerful ways to music and develop a musical self concept. In particular, the link between music and social bonding (Cross, 2009; Hagen and Bryant, 2003) may help to explain the relationship between engagement in group music-making, an enhanced sense of well-being and the development of possible musical selves.

Do musical possible selves contribute to subjective well-being, in later life? The evidence presented in this paper suggests that older people who became actively engaged in musicmaking could, through the medium of music, formulate future-oriented identities that provided a sense of purpose in later life, some extent of sustained autonomy and control and a strong sense of social affirmation. As such, musical possible selves, for these participants, could be interpreted as a mechanism through with individuals could not only sustain but also develop enhanced subjective well-being. Through the context of music-making, individuals could freely experiment with provisional musical selves, which in turn provided structure, a framework for new skills, enhanced confidence, the scope for creative expression and the scope for making valued contributions to the wider community.

These findings have implications for older people themselves as well as for carers and agencies whose focus is the well-being of older people. The findings suggested that even those with little musical background could develop well understood, rich musical possible selves that provided structure, an outlet for autonomous learning and creativity as well as a social context where individuals derived self confidence and self esteem. Moreover, musicmaking was not simply a time-filler or token gesture. Rather, the elaboration of musical possible selves was accompanied in many cases by the acquisition of new skills and 
Creech, A., Hallam, S., Gaunt, H., Pincas, A., McQueen, H., \& Varvarigou, M. (in press). The role of musical possible selves in supporting subjective well-being in later life. Music Education Research.

progression routes in music. Thus, the potential for engagement in music-making to contribute to sustained well-being is clear, suggesting that it is incumbent upon all those concerned with well-being in later life to ensure that appropriate musical opportunities are widely available.

The analysis presented here is limited in scope, particularly as the number of interviewees was relatively small, with little ethnic diversity amongst the sample. An in-depth examination of 'possible selves' was further limited as the interviews did not specifically focus on this construct. It is possible that had the participants been asked specifically about their possible selves a different interpretation would have emerged. Nevertheless, the interpretation presented here suggests that through music many older people found a means by which they were able to formulate well understood and highly esteemed versions of their future selves. This, in turn, may have been a significant factor in helping to navigate the process of ageing in later life with a continuing and even enhanced reservoir of subjective well-being.

\section{Statement of Ethical Approval}

The research reported here conformed to the ethical guidelines stipulated by the British Psychological Society. The research was subject to ethical review and approved by the Ethics Committee of the Faculty of Policy and Society, Institute of Education, University of London.

Word count 7276 (excluding references, including abstract and Tables) 
Creech, A., Hallam, S., Gaunt, H., Pincas, A., McQueen, H., \& Varvarigou, M. (in press). The role of musical possible selves in supporting subjective well-being in later life. Music Education Research.

\section{References}

Ageconcern.org.uk. 2008. The Age Agenda 2008: public policy and older people. London: Age Concern, http://www.ageconcern.org.uk/AgeConcern/Documents/AA_2008_Report.pdf.

Blacking, J.A.R. 1971. Towards a theory of musical competence. In Man: Anthropological essays in honour of O.F. Raum, ed. E. DeJager. Cape Town: Struik.

Blacking, J. 1995. Music, Culture, and Experience. London: University of Chicago Press.

Brookfield, S. (1986). Understanding and facilitating adult learning. San Francisco, CA \& London: Jossey-Bass.

Carterette, E.C., and R. Kendall. 1999. Comparative Music Perception and Cognition. In The Psychology of Music, ed. D. Deustch, 725-92. London: Academic Press.

Coffman, D.D. 2002. Music and quality of life in older adults. Psychomusicology 18 (Spring/Fall):76-88.

Cohen, G.D., S. Perlstein, Chapline, J., J. Kelly, Firth, K.M., and S. Simmens. 2007. The impact of professionally conducted cultural programs on the physical health, mental health and social functioning of older adults - 2-year results. Journal of Aging, Humanities and the Arts 1:5-22.

Cooper, P. and McIntyre, D. (1993). 'Commonality in teachers' and pupils' perceptions of effective classroom learning'. British Journal of Educational Psychology, 63 (3), 381399.

Creech, A., and J. Ellison. 2010. Music in the Early Years. In Music Education in the 21st Century in the United Kingdom, ed. S. Hallam and A. Creech, 194-210. London: Institute of Education, University of London.

Creech, A., Hallam, S., Varvarigou, M., McQueen, H. and Gaunt, H. (2012). 'Active music- 
Creech, A., Hallam, S., Gaunt, H., Pincas, A., McQueen, H., \& Varvarigou, M. (in press). The role of musical possible selves in supporting subjective well-being in later life. Music Education Research.

making: a route to enhanced subjective wellbeing amongst older people'. Perspectives in Public health, 133 (1), 36-43.

Creech, A., Hallam, S., McQueen, H. and Varvarigou, M. (in press). The power of music in the lives of older adults. Research Studies in Music Education.

Cross, I. 2009. The nature of music and its evolution. In The Oxford Handbook of Music Psychology, ed. S. Hallam, I. Cross and M. Thaut, 3-13. Oxford: Oxford University Press.

Cross, S., and H. Markus. 1991. Possible selves across the life span. Human Development $34: 230-255$.

Deci, E.L., and R.M. Ryan. Self Determination Theory: An approach to human motivation and personality 2008 [cited 24 May 2008. Available from http://www.psych.rochester.edu/SDT/publications/pub_well.html.

Frazier, L., P. Johnson, G. Gonzalez, and C. Kafka. 2002. Psychosocial influences on possible selves: A comparison of three cohorts of older adults. International Journal of Behavioral Development 26 (4):308-317.

GOScience. 2008. Foresight mental capital and wellbeing project. London: The Government Office for Science.

Hagen, E.H., and G.A. Bryant. 2003. Music and Dance as a Coalition Signalling System. Human Nature 14 (1):21-51.

Hallam, S. 2010. The power of music: its impact of the intellectual, personal and social development of children and young people. International Journal of Music Education 38 (3):269-289.

Hallam, S., Creech, A., Gaunt, H., Pincas, A., McQueen, H., \& Varvarigou, M. (2013). New dynamics of ageing: Music for life project. Retrieved 6 February 2013, from http://www.newdynamics.group.shef.ac.uk/nda-findings-9.html 
Creech, A., Hallam, S., Gaunt, H., Pincas, A., McQueen, H., \& Varvarigou, M. (in press). The role of musical possible selves in supporting subjective well-being in later life. Music Education Research.

Hodges, D.A., and P.A. Haack. 1996. The influence of music on behaviour. In Handbook of Music Psychology, ed.D. A. Hodges, 29-68. San Antonia: IMR Press.

Huron, D. 2003. Is music an evolutionary adaptation? In The Cognitive Neuroscience of Music, ed.I. Peretz and R. Zatorre, 57-77. Oxford: Oxford University Press.

Ibarra, H. 1999. Provisional Selves: Experimenting with Image and Identity in Professional Adaptation. Administrative Science Quarterly 44 (4):764-791.

Iwasaki, Y., C. Coyle, and J. Shank. 2010. Leisure as a context for active living, recovery, health and life quality for persons with mental illness in a global context. Health Promotion International 25 (4):483-494.

Jamieson, A. 2007. Higher education study in later life: what is the point? Ageing \& Society $27: 363-384$

King, L., and J. Hicks. 2007. Lost and found possible selves: goals, development and wellbeing. New Directions for Adult and Continuing Education 114 (Summer): 27-37.

Laslett, P. (1989). A fresh map of life: The emergence of the Third age. London: Weidenfeld and Nicholson.

Leondari, A., E. Syngollitu, and G. Kiosseoglou. 1998. Academic achievement, motivation, and possible selves. Journal of Adolescence 21 (2):219-222.

Markus, H., and P. Nurius. 1986. Possible Selves. American Psychologist 41 (9):954-969.

Markus, H., and A. Ruvolo. 1989. Possible selves: Personalized representations of goals. In Goal Concepts in Personality and Social Psychology, ed.L. A. Pervin, 211-41. Hillsdale, New Jersey: Lawrence Erlbaum Associates.

Office for National Statistics Online: Centenarians 2011. [cited 21 February 2011]. Available from http://www.statistics.gov.uk/cci/nugget.asp?id=1875.

Pinker, S. 1997. How the Mind Works. New York: Norton. 
Creech, A., Hallam, S., Gaunt, H., Pincas, A., McQueen, H., \& Varvarigou, M. (in press). The role of musical possible selves in supporting subjective well-being in later life. Music Education Research.

R\&RA. 2010. The Relatives and Residents Association. News Release: 40,000 Older People in Care 'Isolated' 2010 [cited 18 November 2010]. Available from http://www.relres.org/pdf/press-releases-articles/RRA_Nov_2010\%20_Isolation.pdf.

Rossiter, M. 2007. Possible selves: An adult education perspective. New Directions for Adult \& Continuing Education (114):5.

Sixsmith, A., and G. Gibson. 2007. Music and the wellbeing of people with dementia. Ageing and Society 27 (1):127-145.

Smith, J. and A. M. Freund. 2002. The Dynamics of Possible Selves in Old Age. The Journals of Gerontology Series B: Psychological Sciences and Social Sciences 57 (6):P492-P500.

Wallin, N., B. Merker, and S. Brown. 2000. The origins of Music. Cambridge, MA: The MIT Press.

Wiggins, R.D., G. Netuveli, E.M. Hyde, E.P. Higgs, and E.D. BLane. The development and assessment of a quality of life measure (CASP-19) in the context of research on ageing 2007 [cited 20 October 2008. Available from http://www.crm.umontreal.ca/Latent05/pdf/wiggins.pdf.

Wiggins, R.D., G. Netuveli, M. Hyde, P. Higgs, and D. Blane. 2008. The Evaluation of a Self-enumerated scale of quality of life (CASP-19) in the context of research on ageing a combination of exploratory and confirmatory approaches. Social Indicators Research 89 (1):61-77.

Withnall, A. 2010. Improving learning in later life. Abingdon, Oxon: Routledge.

Withnall, A., V. McGivney, and J. Soulsby. 2004. Older People Learning: myths and realities. Leicester: Niace with the UK Department for Education and Skills. 
Creech, A., Hallam, S., Gaunt, H., Pincas, A., McQueen, H., \& Varvarigou, M. (in press). The role of musical possible selves in supporting subjective well-being in later life. Music Education Research.

Yong, E. 2009. Secrets of the centenarians. Life begins at 100. New Scientist 7 September (2724):accessed online at http://www.newscientist.com/article/mg20327241.300secrets-of-the-centenarians-life-begins-at-100.html. 
Table 1: I am a musician

(11 sources; 16 references)

- It has made a big difference to my life. After retiring at 59, I now (65 now) consider that I have become a musician. I write songs, I perform and I play guitar.

- Relatives, friends, some of them are quite intrigued. Particularly when you mention the Sage they think you are a wonderful singer.

- ...if you are there playing along with the other musicians, playing along the tune and you are, probably, knowing the tune, as well you are still reading. So, that [learning how to read music] would be nice, yea...

- It's good being with people who appreciate music and we can talk about it, because lots of people they aren't really that much interested in it, do they? So, it is good doing that down here, yes.

- It is brilliant now, because we gave a concert just before Christmas and the audience were amazed. My daughter was there and she couldn't believe it. Because they encouraged us, you know, to dress like rock in leathers and other stuff and you should see the pictures.

- You stop counting your rhythm you feel it in your blood.

- Do you see yourself as a musician? - Yes, I do

- I think if I was doing that on my own I wouldn't feel like a musician but when I hear the sound of everybody playing together [I feel].

- In the beginning I was very embarrassed about singing and anybody hearing me sing. So I always chose a good singer next to me so that she would carry me along, you see. But now, no, I am not embarrassed any more. I feel my voice has developed.

- The guitar is always in the ring now. It's always around the house. I will pick it up and play. 
Creech, A., Hallam, S., Gaunt, H., Pincas, A., McQueen, H., \& Varvarigou, M. (in press). The role of musical possible selves in supporting subjective well-being in later life. Music Education Research.

Table 2: Music as a new opportunity

(31 sources, 40 references)

- This is the first time in my life that I have played an instrument with a group.

- My life before retirement was rarely my own. I was always at someone else's bidding and on a strict time schedule. In the last 3 years I have claimed back my life. I decided, amongst other things, to start to learn about music and start to play an instrument, something I had always wanted to do. There have been real changes trying to learn the piano from scratch and the theory is mentally exercising. The real FUN for music however has come from the Ukulele group where I enjoy the social contacts, the thrill of making music in a group and, of course, the challenge of having to play an instrument.

- I have always wanted to learn to play a musical instrument and I feel so pleased and satisfied that I am here learning to play instead of just listening.

- I think that it gives people an opportunity then to see where they might get and give them a sort of target - 'I could get this, couldn't I? 
Creech, A., Hallam, S., Gaunt, H., Pincas, A., McQueen, H., \& Varvarigou, M. (in press). The role of musical possible selves in supporting subjective well-being in later life. Music Education Research.

Table 3: Rediscovering lost musical possible selves 


\section{Connection with positive memories and past musical possible selves}

(23 sources; 38 references)

- From a very early age music was always in my life. My father had his own dance band, my mother played the piano.

- Both my parents could sing, in fact my mother went to the Royal College of music with her sister. My father had a nice light baritone voice and they did a lot of amateur musicals, musical performances, you know. Gilbert and Sullivan things. So, there was a sort of feeling of music although I fell foul of a music teacher at boarding school with who I did not get on with and I dropped the piano and I always rather regret it. I wish I had learned the instrument properly then. But I think I sort of caught up a little bit.

- Involvement and interest in music. Forever. Well if you start with say 5, 6, 7, me and my sister used to go to bed not with bedtime stories but with the National Song Book, and we used to sing the ones we knew, we'd learned at school, we used to sing those till we went to sleep, if we didn't know what the tune was we made one up.

- I started piano when I was about 13, 14, something like that and carried on until, more or less until I left school. And I did a little bit of evening class when I was about 25, I did a duet class but that sort of folded, when I got married. And I promised myself when I was 60 I would restart learning the piano because I wouldn't be able to sing any more but because I can still sing I haven't started to play the piano!

- I played when I was very young. I played in a group and then I played in a band until my early twenties. But then I had the guitar around more like an object and played a bit but not played with any discipline for years. Not played with rhythm, drums and all these things you need.

- I have had a love of music all my life from a very young age. During my school years and early adulthood I was always part of a choir. After marriage this was stifled somewhat. But now that I am divorced and I have a partner of similar interests the doors are once more opening to me. My partner and I watch a live band every week. We are proof that over 50 isn't the end of life and enjoyment.

Redefining negative memories and lost musical possible selves

5 sources; 15 references

- My mum used to sing and my grandfather used to sing and I used to think 'I can't sing like them'. So I didn't.

- We meet a lot of older people who say 'oh, I can't sing like I used to'. They feel like they lost their confidence with their voice and they might say 'I'd love to sing but, you know, it's not very good these days'. And I have met a lot of people like that who just think 'I am too old, I can't sing anymore'.

- The other thing I find is when I tell my friends about here, the thing I get back is 'I can't read music' and I try to explain to them that you don't have to for a lot of the groups.

- At primary school I have been told that I could not sing and so had never attempted to do so. After taking singing lessons for 18 months I joined a choir and can honestly say that it added a new dimension to my life. I could never call myself a singer but I love singing and I know the joy I feel spills over to all areas of my life. 
Creech, A., Hallam, S., Gaunt, H., Pincas, A., McQueen, H., \& Varvarigou, M. (in press). The role of musical possible selves in supporting subjective well-being in later life. Music Education Research.

\section{Figure 1: Possible selves and the three factors of well-being}

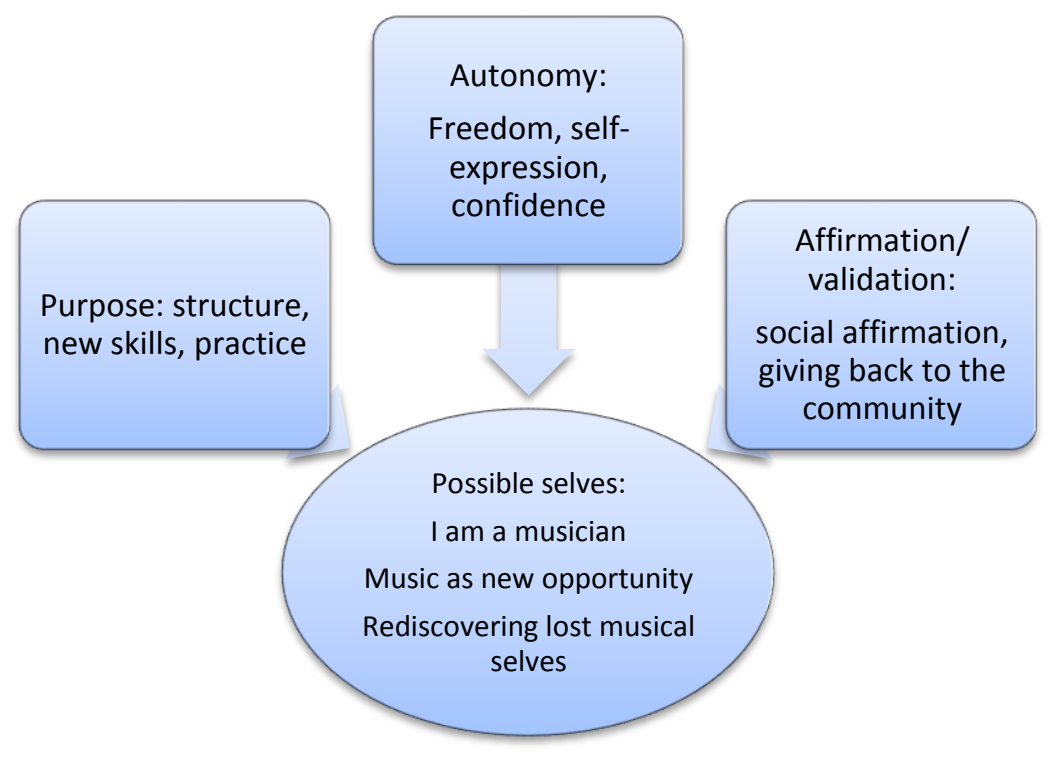


Creech, A., Hallam, S., Gaunt, H., Pincas, A., McQueen, H., \& Varvarigou, M. (in press). The role of musical possible selves in supporting subjective well-being in later life. Music Education Research.

Table 4: Purpose

\section{Structure}

(17 sources, 23 references)

- I look forward to my three singing groups each week and while a commitment I loved attending.

- The thing I liked about this is that all people who really enjoyed it and wanted to be there were very determined and they were there every Tuesday come day in come out. They always had it in their diary - I am coming down for the music classes.

- It has also taught me to arrange my other activities in such a way that I can fit in time for practice and consolidating my skills.

- You need to have some new routine if you stop working every day, and so on Tuesday mornings I go to music, and I'm amazed, actually, at how much everybody knows.

\section{New skills}

(38 sources, 43 references)

- I have a sense of achievement at learning something new.

- I get a feeling of doing something better each week and definitely feel I am learning and improving while enjoying myself. One of the best things I have ever taken part in. I love it!

- I have heard many of the pieces before so it's very interesting for me to be able to play them myself.

- Making progress and learning new skills helps overcome feelings that I am no longer capable of doing certain things.

- Has helped me to know that whatever age you are there is still something new and magic out there to enjoy.

- Has helped me to stay open minded, take risks and form new friendships as of which continue to be important in older age.

- You feel 'Oh, yes we have accomplished something'.

\section{I have to practise}

(5 sources, 5 references)

- I would like to practise more.

- I find it hard to learn the tunes and have to practice a lot. I wouldn't want to stop singing in a choir.

- I practise every day for half an hour - my wife practises at one end of the house and I practise at the other. 
Creech, A., Hallam, S., Gaunt, H., Pincas, A., McQueen, H., \& Varvarigou, M. (in press). The role of musical possible selves in supporting subjective well-being in later life. Music Education Research.

Table 5: Autonomy/control

\section{Freedom}

( 2 sources, 2 references)

- The freedom to enjoy and participate in music has changed my life dramatically.

- My life before I retired was rarely my own. I was always at someone else's bidding and on a strict time schedule. In the last 3 years I have claimed back my life. I decided, amongst other things, to start to learn about music and start to play an instrument, something I had always wanted to do.

\section{Self expression}

(8 sources, 9 references)

- I enjoy the opportunity to sing, express myself and be creative.

- Very important as a means of emotional expression and as a mood enhancer, especially in winter.

\section{Confidence}

(32 sources, 44 references)

- It has given me more confidence in singing occasionally on my own as well.

- You Rock and Roll and you come out thinking 'that's quite good. I have never done that' and it broadens your horizons.

- It's made a tremendous difference to my life; absolutely amazing. Yesterday I lost my buspass. Now, before I started coming here, you know, I don't have depressions anymore which I used to have. Before it would be like 'I lost my bus-pass? Panic attack! I would freak out' but I just thought 'ok, I lost my bus pass, never mind, I'll ring up in the morning and go and do what I have to do. That's what I thought quite calmly.

- I would never sing in front of anybody but now I just simply head up.

- I have confidence now that with the help of the teacher tutoring me, that one day I'll be able to play.

- I used to sit outside the door listening to the music until I got caught! (The facilitator) said come in.

- Sometime you can go to a bar and sing some karaoke or something, once you've got the confidence.

- You're not shy or anything because we're doing a practical together. 
Creech, A., Hallam, S., Gaunt, H., Pincas, A., McQueen, H., \& Varvarigou, M. (in press). The role of musical possible selves in supporting subjective well-being in later life. Music Education Research.

Table 6: Musical performance as a source of affirmation and validation

\section{Social affirmation through performance}

(23 sources, 28 references)

- I can now sing in tune and I am so excited and longing for our gala concert and to hear my family's reaction. No one else in the family has done anything like this.

- First we sing as a choir, then on our own. It gives me, at my age [tearful] I'm 85, it gives me a great feeling inside me that I can sing.

- I get a sense of achievement from participation especially when we perform for an audience.

- You feel that it's a nice ending to weeks and weeks of hard work, you know. You feel great! That's good. I feel satisfied now, you know. That you've done something and somebody else has appreciated it.

- [On 'token' performances] To do the performances here I've often found frustrating because they are often very brief. We are coming from a long way away and we play for ten minutes, you know. Why are we bothered?, you know. There is always a lot of people to fit in and the other thing is they are usually put in a noisy environment...Now, recorders are quiet instruments. If we had trombones we could dominate but with recorders...

- [On 'token' performances] I am not interested in going out, I wouldn't want to go out and have a performance to an audience. To the group or if for argument's sake there was an old people's do and we went down to sing and they wanted me to do a solo, I'd do a solo. If it's one that's within my repertoire - good God, using that word! That's funny.

\section{Giving back to the community}

(12 sources, 22 references)

- I have made new friends, I am able to support people less experienced in their music-making and enjoy teaching beginner recorder to adults.

- It proved that I can do it and elevated my self-esteem. And has given pleasure to others.

- you are allowing people to hear you; you want to give a rendition of yourself ... You want to feel that what you've learnt is going to be enjoyed by someone else.

- It makes me feel good as well. I like to make people feel good, I like the audience to be happy, that's it, an entertainer.

- It means a lot to us, it means a lot to our group leader, and when we go out from here sometimes to hospitals or other old people's homes and we sing to them, it's marvellous.

- I get a wonderful feeling inside me to see, me singing or the group singing, the happiness it gives to these other people.

- It's a wonderful feeling that you could still sing a song and entertain people. It just does, it does me a world of good. Sometimes I sit here with the window open and ladies on the other side say I heard you singing this morning, Harry, it was lovely. 